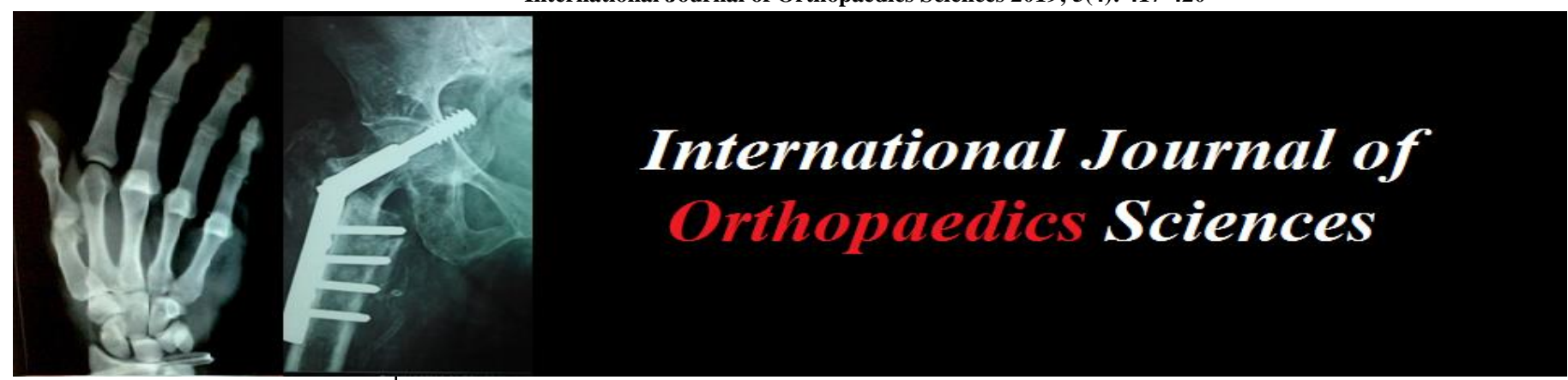

E-ISSN: 2395-1958

P-ISSN: 2706-6630

IJOS 2019; 5(4): 417-420

(C) 2019 IJOS

www.orthopaper.com

Received: 06-08-2019

Accepted: 10-09-2019

\section{Pritesh Patel}

Senior Resident Doctor,

Department of Orthopaedics,

PDU Medical College, Rajkot,

Gujarat, India

Anurag Ajudiya

Senior Resident Doctor,

Department of Orthopaedics, PDU Medical College, Rajkot, Gujarat, India
Corresponding Author:

Pritesh Patel

Senior Resident Doctor,

Department of Orthopaedics,

PDU Medical College, Rajkot,

Gujarat, India

\section{Outcomes of traumatic thoracolumbar fractures managed with Pedicular screw fixation system: A study of 25 cases}

\section{Pritesh Patel and Anurag Ajudiya}

DOI: https://doi.org/10.22271/ortho.2019.v5.i4h.1709

Abstract

Thoracolumbar spine trauma is important burden of society. Early operative measures brings up better outcomes then conservative management posterior screw fixations has its own benefits in terms of outcomes. The goals of treatment in thoracolumbar fractures are restoring vertebral column stability and obtaining spinal canal decompression, leading to early mobilization of the Patient.25 patients were operated for traumatic thoracolumbar vertebral fractures prospectively. Outcomes were measured on basis of frankle grade, complications and clinically. Thoracolumbar neurosurgical problem in road traffic accidents and fall from height; more commonly involve thoracolumbar junction; D11 to L2 region, It may be of burst compression and fracture dislocation type or wedge compression type. Surgical treatment is a better option for ambulation and faster recovery then conservative management.

Keywords: Thoracolumbar spine, frankle grade, pedicular screw, vaccaro score

\section{Introduction}

The goals of treatment in thoracolumbar fractures are restoring vertebral column stability and obtaining spinal canal decompression, leading to early mobilization of the patient ${ }^{[1]}$ The appropriate treatment of thoracolumbar fractures remains a subject of controversy [2, 3]. Different schools of thoughts for each modality, ranging from conservative management with reduction by pillow and extending today to anterior/posterior instrumentation systems for fixation, have proved that neither is an ideal method and much more needs to be done to reach an ideal modality of management ${ }^{[2,4,5]}$.

\section{Aims and Objectives}

1. To study the functional outcomes of pedicular screw fixation system for thoracolumbar vertebral fractures.

2. To evaluate the effectiveness of pedicular screw in thoracolumbar vertebral fractures.

3. To evaluate complications, rate of infection, rate of improvement correction of wedge angle and vertebral height after fixation with pedicular screw.

4. To assess the overall results of thoracolumbar vertebral fractures and its management with pedicular screw.

\section{Materials and Methods}

Thirty patients with posttraumatic instability of lower thoracic or upper lumbar spine were surgically managed at the department of Orthopaedics, Rajkot. All those patients who were operated for thoracolumbar junction injuries with pedicle screw fixation were included.

The patients with preexisting systemic illness or associated extra spinal injuries significant enough to result in increased morbidity or mortality were excluded from the study. all patients underwent open reduction and internal fixation by posterior approach. Laminectomy to decompress spinal cord was carried out at the involved level and bone was saved to be used as bone graft. 


\section{Inclusion Criterias}

1. age $>18$ years and $<65$ years

2. traumatic spinal injuries with Vaccaro score $>=4^{[12]}$

3. willingness of the patient

4. history of fall from height, motor vehicle accident and other injuries with significant neurological compromise

5. failure of conservative rehabilitation program

\section{Exclusion Criterias}

1. Age $<18$ years and $>65$ years
2. Noncompliant patient

3. Underlying non traumatic spinal diseases

4. Vaccaro score $<4{ }^{[12]}$.

\section{Observations and Analysis}

Table 1: Sex Distribution

\begin{tabular}{|c|c|c|}
\hline Sex & Number & Percentage \\
\hline Male & 11 & $44 \%$ \\
\hline Female & 14 & $56 \%$ \\
\hline
\end{tabular}

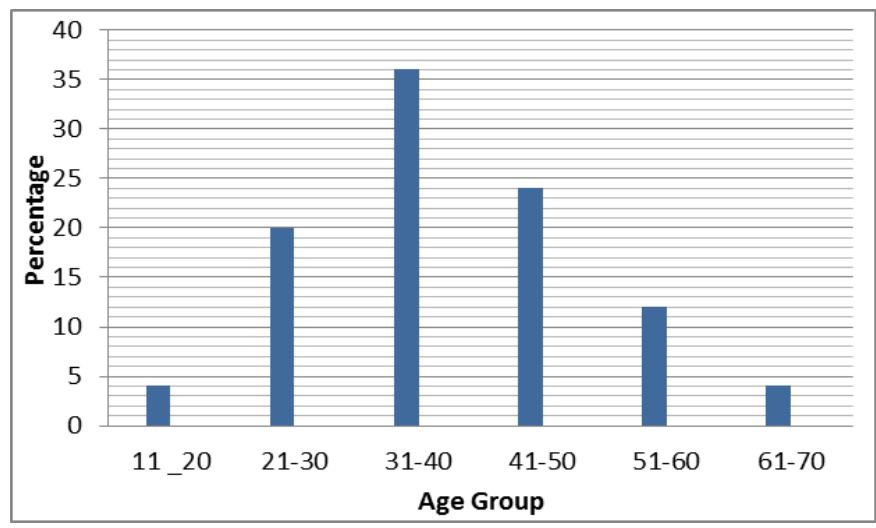

Fig 1: Age Group

This table shows age distribution in our study which shows that 30 to 40 years of age group has maximum chances of this injury $(36 \%)$. whereas extremes of age have lower incidence of thoracolumbar vertebra fractures.

Table 2: Mode of Injury

\begin{tabular}{|c|c|c|}
\hline Mode of injury & Number & Percentage \\
\hline Fall from height & 21 & 84 \\
\hline Road traffic accident & 4 & 16 \\
\hline
\end{tabular}

This table suggests type of injury in patients with from height (84\%). thoracolumbar fractures. Most common type of injury is fall

Table 3: Level of vertebral injury

\begin{tabular}{|c|c|c|}
\hline Vertebral level & Frequency & Percentage \\
\hline D10 & 1 & $4 \%$ \\
\hline D11 & 1 & $4 \%$ \\
\hline D12 & 10 & $40 \%$ \\
\hline L1 & 7 & 28 \\
\hline L2 & 3 & 12 \\
\hline L3 & 1 & 4 \\
\hline L4 & 1 & 4 \\
\hline L5 & 1 & 4 \\
\hline TOTAL & 25 & 100 \\
\hline
\end{tabular}

This table shows level of vertebra injured in pathology; maximum chance is at dorsolumbar junction (D11-L2). D11 shows more predominant injury among it (40\%) whereas higher level of vertebra is less commonly involved.

Table 4: Type of Fracture

\begin{tabular}{|c|c|c|}
\hline Type of fracture & Frequency & Percentage \\
\hline Burst & 9 & 36 \\
\hline Wedge Compression & 14 & 56 \\
\hline Fracture dislocation & 2 & 8 \\
\hline Total & 25 & 100 \\
\hline
\end{tabular}

This table shows type of pathology in vertebral fractures. there are 3 most common pathology. Burst, wedge compression and fracture dislocation. Most common pathology is being wedge compression type (56\%) and least common among all is fracture dislocation type (8\%)

Table 5: Injury Surgical Interval

\begin{tabular}{|c|c|c|}
\hline Injury surgical interval & Frequency & Percentage \\
\hline$>7$ DAYS & 16 & 64 \\
\hline <7 DAYS & 9 & 36 \\
\hline Total & 25 & 100 \\
\hline
\end{tabular}

This table shows injury surgical interval of our patients; out of 25 patients; 16 patients were operated more than 7 days of injury (64\%) and 9 patients were operated in less than 7 days of injury (36\%). no patient was operated within 48 hours of injury. 
Table 6: Improvement of franked grade

\begin{tabular}{|c|c|c|}
\hline Number of Patients & Improve in grade & Percentage \\
\hline 3 & 0 & $12 \%$ \\
\hline 4 & 1 & $16 \%$ \\
\hline 3 & 2 & $12 \%$ \\
\hline 7 & 3 & $28 \%$ \\
\hline 8 & 4 & $32 \%$ \\
\hline
\end{tabular}

Above table shows that Out of 25 patients 3 patients had no improvement 4 had improvement in 1 grade, 3 had improvement in 2 grades, 7 had improvement in 3 grades, 8 had improvement of 4 grades.
Table 7: Complications of Pedicular Screw

\begin{tabular}{|c|c|c|}
\hline Complication & Frequency & Percentage \\
\hline Infection & 2 & $8 \%$ \\
\hline Implant loosening & 2 & $8 \%$ \\
\hline Bedsore & 3 & $12 \%$ \\
\hline None & 18 & $72 \%$ \\
\hline
\end{tabular}

This table shows postoperative complication of pedicular screw fixation. out of 25 patients 21 had no complication and 2 had implant loosening and 2 patients had postoperative infection.

\section{Discussion}

Table 8: Age Comparision

\begin{tabular}{|c|c|c|c|}
\hline Age group & Current Study 2017 & Roopsingh et al. & Shailendra Khare et al. 2003 \\
\hline $11-20$ & $4 \%$ & $7.2 \%$ & - \\
\hline $21-30$ & $20 \%$ & $18.6 \%$ & $44.0 \%$ \\
\hline $31-40$ & $36 \%$ & $27.8 \%$ & $28 \%$ \\
\hline $41-50$ & $24 \%$ & $24.2 \%$ & $20 \%$ \\
\hline $51-60$ & $12 \%$ & $12.0 \%$ & $8.0 \%$ \\
\hline $61-70$ & $4 \%$ & $10.4 \%$ & - \\
\hline Total & $100 \%$ & $100 \%$ & $100 \%$ \\
\hline
\end{tabular}

In our study maximum patients are in the age group 31-40 years and mean age is 39.7 years which can be comparable to study of Roopsingh et al. in which maximum patients are in the same age group (27.8\%) and Shailendra Khare et al. included 25 patients in his study in which maximum patients are in 16- 25 years of age group (44\%). and in Naushad Husain et al. has included in 33 patients in study maximum patients being in 30-40 years of age and mean age is 37.6 years. Ling wang et al. has included 20 patients in his study in which mean age group is 38.4 years.

Table 9: Gender Comparison

\begin{tabular}{|c|c|c|c|c|c|}
\hline Sex & Current study & Roop Kumar et al. & Naushad Hussain et al. & Ling Wang et al. & Shailendra Khare et al. \\
\hline Male & $44 \%$ & $70 \%$ & $91 \%$ & $75 \%$ & $72 \%$ \\
\hline Female & $56 \%$ & $30 \%$ & $9 \%$ & $25 \%$ & $28 \%$ \\
\hline Total & $100 \%$ & $100 \%$ & $100 \%$ & $100 \%$ & $100 \%$ \\
\hline
\end{tabular}

In our study we have included 25 patients in which 14 are female and 11 male as compared to Roopkumar et al. has included 66 patients in his study in which there are 46 male and 20 females and Naushad Hussain et al. has included 33 patients in their study in which 3 were females and 30 were males. As compared to Ling Wang et al. has included 20 patients in which 15 were males and 5 were females and Shailendra Khare et al. included 25 patients in which 18 were males and 7 were females.

\section{Comparison of mode of injury}

The commonest mode of injury in our study was fall from height which coincides with Shailendra Khare et al. in which 12 patients had similar history and 8 patients had road traffic accident. Whereas in study of Roy Camille et al. and Howards et al. accounted road traffic accidents in majority of cases.

Table 10: Comparison of level of vertebra

\begin{tabular}{|c|c|c|c|}
\hline Vertebral level & Current study 2017 N=30 & Shailendra Khare et al. $\mathbf{N = 0 7}$ & Ling wang et al. $\mathbf{n = 2 0}$ \\
\hline D9 & - & $14.3 \%$ & - \\
\hline D10 & $4 \%$ & $14.3 \%$ & - \\
\hline D11 & $4 \%$ & - & - \\
\hline D12 & $40 \%$ & $28.6 \%$ & $10 \%$ \\
\hline L1 & $28 \%$ & $28.6 \%$ & $45 \%$ \\
\hline L2 & $12 \%$ & $14.3 \%$ & $15 \%$ \\
\hline L3 & $4 \%$ & - & $5 \%$ \\
\hline L4 & $4 \%$ & - & - \\
\hline L5 & $4 \%$ & - & - \\
\hline T1 & - & - & \\
\hline
\end{tabular}

In our study most common vertebral level is D11- L2 which is dorsolumbar junction. As compared to Roopkumar et al. studied that 58 patients had single vertebral fractures, 8 had 2 or more vertebral fractures. The level of single vertebral fractures was maximum at L1 level followed by D12 and D11 levels which coincides with Ibrahim et al.

\section{Injury surgical interval}

In our study; out of 25 patients; 20 patients were operated within 7 days of injury $(66.6 \%)$ and 10 patients were operated more than 7 days of injury $(33.3 \%)$. no patient was operated within 48 hours of injury.

Roopsingh et al. showed the mean time interval between 
injury and surgery was 13.1 days (range, 3-31 days). Patients were divided further in two groups for analysis. Group 1 included patients that were operated within 7 days (early surgery group, $\mathrm{n}=20)(30.3 \%)$ and group 2 included patients that were operated after 7 days (late surgery group, $n=46$ ). (69.9\%) The two groups were compared to evaluate whether timing of surgery had any effect on the final outcome.

Table 11: Post op complication

\begin{tabular}{|c|c|c|c|}
\hline & Current study 2017 $\mathbf{n = 7}$ & Shailendra Khare et al. $\mathbf{n}=\mathbf{1 3}$ & Chadha et al. $\mathbf{N}=\mathbf{1 2}$ \\
\hline Wound infection & $28.7 \%$ & $7.7 \%$ & $16.7 \%$ \\
\hline Implant loosening & $28.7 \%$ & $23.2 \%$ & $8.3 \%$ \\
\hline bedsores & $3 \%$ & $30.8 \%$ & $33.3 \%$ \\
\hline UTI & - & $38.4 \%$ & $41.7 \%$ \\
\hline
\end{tabular}

In our study post of complication were implant loosening and wound site infection. As compared to Shailendra et al. showed wound infection bedsore and implant loosening and UTI. and chadha et al. showed maximum chances of UTI in postoperative patients. Katonics showed in his study that $1 \%$ of iatrogenic neurologic insults secondary to erroneous placement of screw.

\section{Conclusion}

Thoracolumbar injury is a common neurosurgical problem in road traffic accidents and fall from height. Thoracolumbar injuries are more commonly involve thoracolumbar junction; D11 to L2 regionIt may be of burst compression and fracture dislocation type most commonly being wedge compression type. Surgical treatment is a better option for early ambulation and faster recovery then conservative management. An early/immediate surgery in the form of pedicle screw fixation with decompression provides better relief in neurological recovery also.

\section{References}

1. Knop C, Fabian HF, Bastian L et al. Fate of the transpedicular intervertebral bone graft after posterior stabilisation of thoracolumbar fractures. Eur. Spine J. 2002; 11:251-257.

2. Yue JJ, Sossan A, Selgrath C et al. The treatment of unstable thoracic spine fractures with transpedicular screw instrumentation: a 3-year consecutive series. Spine (Phila Pa 1976). 2002; 27:2782-2787.

3. Modi HN, Chung KJ, Seo IW et al. Two levels above and one level below pedicle screw fixation for the treatment of unstable thoracolumbar fracture with partial or intact neurology. J Orthop Surg Res. 2009; 4:28.

4. Dai LY, Jiang LS, Jiang SD. Conservative treatment of thoracolumbar burst fractures: a long-term follow-up results with special reference to the load sharing classification. Spine (Phila Pa 1976). 2008; 33:25362544.

5. Shin TS, Kim HW, Park KS, Kim JM, Jung CK. Shortsegment pedicle instrumentation of thoracolumbar burstcompression fractures: short term follow-up results. J Korean Neurosurgery Soc. 2007; 42:265-270.

6. Roopsingh et al. outcomes of pedicular screw fixation and monosegmental fusion in fresh thoracolumbar fractures, PGIMS Rohtak, India. Asian Spine J. 2014; 8(3):298-308.

7. Khare S, Sharma V. Surgical outcome of posterior short segment trans-pedicle screw fixation for thoracolumbar fractures. Journal of orthopaedics. 2013; 10(4):162-7

8. Hussain N, Patil ND, Patel H, Shakya A. Short segment pedicle screw fixation of thoracolumbar fracture: a case series of 33 patients. International Journal of Research in Orthopaedics, 2017.
9. Wang L, Li J, Wang H, Yang Q, Lv D, Zhang W et al. Posterior short segment pedicle screw fixation and TLIF for the treatment of unstable thoracolumbar/lumbar fracture. BMC musculoskeletal disorders. 2014; 15(1):40.

10. Roy-Camille et al. osteosynthesis of thoracolumbar spine with metal plates screwed through vertebral pedicles, 1976.

11. Chadha M, Bahadur R. Steffee variable screw placement system in the management of unstable thoracolumbar fractures: A third World experience. Injury. 1998; 29:737-42. 